\title{
Developing a Useful, Personal Range Science Library
}

\author{
JOHN F. VALLENTINE
}

Small reference libraries-whether personal, departmental, or the literature pool of a group of specialists - can be very valuable and readily available bibliographic, teaching, and research tools. However, their utility will be realized only when systematically collected, adequately indexed, and consistently used.

Personal libraries should include the most useful books, reprints, and other materials based on present and anticipated needs. Materials included in the personal library should be carefully selected to include the needed materials while minimizing filing space and facilities needed and difficulties of moving the files when necessary.

Personal libraries will include a selected list of reference books, textbooks, and manuals. A personal collection of such monographs seldom will be large enough to require indexing but merely requires a bookcase for placement. However, the bulk of most personal files will generally consist of the pamphlet or reprint file-collectively referring to reprints, bulletins, booklets, manuscripts, pamphlets, typed and mimeographed reports, and similar materials. This file will require regular, systematic filing-indexing.

\section{Obtaining Reprints and Bulletins}

Much of the non-book range science literature is free or inexpensive and can be obtained readily. Reprints of journal articles are generally provided as a courtesy by authors to associates and others requesting and demonstrating need of such. Reprints requested for one's personal library should generally exclude those key journals to which the requester subscribes and should consist only of the occasionally desired article included in peripheral or secondary journals. Reprints can frequently be obtained, particularly after the author's supply is exhausted, for a moderate fee from the publisher or a reprint company.

Journal reprints - also referred to as separates - are advantageous in that they generally pertain to a single subject and are readily fileable by subject. Besides being an economical source of information and providing a ready means of building up a literature file, reprints provide a minimum of bulk and extraneous material. Reprints should be provided with complete bibliographic information; such information should be added to the extent not printed by the publisher on the reprints.

Bulletins published by state agricultural experiment stations, state extension services, USFS Forest and Range Experiment Stations, and other USDA publications, including monographic series and special ARS (now SEA-AR) publications, are prime sources of range science information. These organizations maintain mailings for sending out new lists of available publications as they are published. From these lists can be selected and ordered free or low cost publications for the pamphlet file. Preprinted postcards for requesting reprints and bulletins are in common use by scientists. Also, photocopying at local libraries is a readily available means of obtaining copies of out-of-print or otherwise unobtainable originals.

\section{Filing Reprints and Bulletins}

Reprints and bulletins can be readily filed in filing boxes or file drawers. However, as the reprint file begins to grow beyond a few dozen, its usefulness decreases rapidly unless an effective filing system is developed. Materials in the reprint file must be so located

Author is professor of range science, Brigham Young University, Provo, Utah. Manuscript received April 9, 1979. that they can be retrieved quickly. However, the complexity of the filing system accepted for use is a matter of great concern. The system must be adequate to meet the designs for the file and should be sufficiently versatile to accommodate future expansion.

Since regular library classification systems such as Dewey and LC are totally unadapted for the small range science or rangerelated reprint library, the following alternatives for filing systems might be considered.

\section{Filing by Subject Matter}

Materials are filed by subject matter categories in labeled filing boxes or filing drawers. When both primary and secondary subject categories are used for filing, this system can accommodate up to about 2,500 items but becomes unwieldy with larger collections.

The principal advantages of this filing system are that it provides quick reference, materials on related subject matter are grouped together, and card indexing is not required. Disadvantages include the following: (1) the number of reprints in some categories may become too numerous for rapid sorting, (2) some items of general or multiple-subject nature are not readily classified into a single category, (3) a file folder or file box must be provided for each subject category, and (4) classification will generally have to be done by a scientist.

Since no master list of contents of the file is generally maintained, control on number of copies of each separate and recognition of losses from the file may not be readily effected. It will generally be desirable to label all items by subject or subject matter symbols to expedite refiling. This system is best adapted to small collections not expected to grow materially but is impractical for large collections.

\section{Filing by Author}

Materials are filed by author and, if needed, subsequently by year of publication. Filing is greatly simplified, but use is dependent upon the user associating subject matter with individual authors. Unless provided with a subject matter card index, this filing system will probably prove ineffective for reprint files. However, an adequate card index might well make this a usable system, but filings and refilings may become complex with large collections. A master list or catalog of materials in the file is generally not included in this simplified system.

\section{Filing by Numerical Order of Receipt}

Materials are numbered and filed consecutively as received. When provided with a comprehensive card index, this filing system has proven effective for even large reprint files. Multiple subject cards permit cross indexing when required. A master list of materials arranged by file numbers and including bibliographic entries is generally maintained to enable scanning by entry periods, noting sequence of additions to the file, correcting mislabeling on reprints, and replacing lost items.

Advantages of this system include ease of filing, retrieval (once the file number is located), and refiling; expansion is mostly unlimited; filing boxes and drawers can be kept full; and materials can be sorted by size and placed in different portions of the file. First and last numbers should be placed on file boxes or file drawers for rapid retrieval.

The effectiveness of this filing system is directly dependent upon development and maintenance of a comprehensive subject matter card index. Disadvantages of this system are that subject matter classification must be done by the scientist, and secretarial assistance is needed in making and filing the file cards. A material 
advantage of such a subject matter index is that it permits interfiling of cards for book titles, chapters within books, articles from intact journals, and even materials not included in the personal library but filed elsewhere. A four-level subject classification and filing system specially developed for range science can be found in U.S. Canadian Range Management, 1935-19771. Modifications, however, should be made to meet special needs.

A three-card indexing system for a reprint library has been described in Wildlife Management Techniques. ${ }^{2}$ One card is filed by primary subject matter, the second card is filed alphabetically

${ }^{1}$ Vallentine, John F. 1978. U.S.-Canadian Range Management, 1935-1977: A Selected Bibliography on Ranges, Pastures, Wildlife, Livestock, and Ranching. Oryx Press, Phoenix, Ariz. abt 368 p. $(81 / 2 \times 11$ in. $)$.

${ }^{2}$ Burns, Robert W., Jr., and Henry S. Mosby. 1971. Developing and Maintaining a Small Personal Reprint Library. In Robert H. Giles, Jr. (Ed.). Wildlife Management Techniques (3rd Ed.). The Wildlife Society, Washington, D.C.; p. 47-51. This section also explains the use of edge-notched index cards and their retrieval on a subject matter basis with the use of sorting needles. by author, and the third card is filed numerically, thereby providing a master list. This indexing system permits materials to be readily located by author, subject, or number. An alternative indexing system used and recommended by the author combines the use of a subject matter card index $(3 \times 5$ inch) with duplicate copies as needed for cross filing with numerically entering complete bibliographic information on $81 / 2^{\prime \prime} \times 11^{\prime \prime}$ sheets placed in a three-ring binder. An author index card file was found insufficiently used to justify continuation and was deleted.

Filing by Primary Subjects and Then by Numerical Order of Receipt

This system is identical to the previous system except that materials are first sorted by primary subject matter categories before numbering. This additional preliminary step is unnecessary if the materials selected for the reprint file are restricted to range science and range-related subjects. However, it might be useful and desirable if the reprint library is to represent multiple disciplines rather than range science solely.

\title{
Volunteer Paper Solicitation
}

\author{
1982 SRM Annual Meeting, Calgary, Alberta \\ February 8-12, 1982
}

\section{Program Committee}

Alex Johnston (Chairman)

Eldon Edwards

A.W. Bailey

W. James Clawson

Robert M. Hyde

William J. Little

Ing. Donald Johnson

John Fisher

Willie Milliron

Charles M. Colton

J. Daniel Rogers

Wm. W. Mitchell

Melvin S. Morris

Steven S. Waller

Send titles and abstracts to:

Alex Johnston
c/o Lands Division, AENR
Sun Center
530 - 8th Streeth South
Lethbridge, Alberta
Canada T1] 2]8

Alex Johnston

AENR

530 - 8th Streeth South

Canada T1) 2J8
Papers for the 1982 SRM Annual Meeting will be solicited in ten general categories. You are encouraged to participate. A formal call for titles and abstracts will be issued in June and you will be asked to submit them by August 15.

\section{General program categories are:}

1. Range animals-production; diets and nutrition; wildlife; insects; other animals.

2. Range plants-collection; selection and breeding; germination and establishment; physiology; morphology; taxonomy.

3. Soil and water-range watershed management; rangeland hydrology; grazing and water management; soil fertility and management.

4. Range ecology and rangeland ecosystems-succession; fire nutrient cycling; drought; ecosystem classification.

5. Range management systems-grazing systems; forest grazing; complementary forages; grazing impact.

6. Range inventory and evaluation-range inventory; survey methods; condition and trend; land capability.

7. Range improvement and land reclamation-renovation; seeding; brush and weed control; fertilization; reclamation and stabilization of disturbed lands.

8. Sociological and political concerns-history; education; communications; technology transfer; international programs.

9. Range economics and management-production costs and returns; modeling; computer utilization.

10. Ranching practices-ranching experiences; enterprise concerns; technology integration.

The following policies will apply to volunteer papers:

1. An individual shall not author or co-author more than one paper persion.

2. Titles and abstracts will be due August 15, 1981. These abstracts will be printed without editing and will form the basis of selection of papers for presentation.

3. Papers will be $\mathbf{1 5}$ minutes in length; there will be a 5 -minute discussion on each paper. Participants are expected to attend as a condition of acceptance.

4. Titles and abstracts received after the due date will be considered as alternates.

5. Notification of acceptance/rejection will be in your hands by November 1, 1981. 